\title{
EFEITO DO MUTANTE «EBONY» DE DROSOPHILA MELANOGASTER NA VIABILIDADE LARVAL
}

\author{
FĀBIO DE MELO SENE \\ LUIZ EDMUNDO DE MAGALHÃES \\ Dept. ${ }^{\circ}$ de Biologia do Instituto de Biociências da USP.
}

\section{RESUMO}

São apresentados dados de viabilidade pré-adulta de diferentes genótipos de 100 larvas com diferentes composições.

Foram usadas 4 linhagens diferentes, $E_{1}$ ("ebony") e $B_{1}$ (selvagem) do laboratório e $\mathrm{E}_{2}$ e $\mathrm{B}_{2}$ extraídos de uma caixa de população depois de 20 gerações de competição entre os alelos.

Os resultados do experimento com as moscas $E_{2}$ e $B_{2}$ são diferentes dos obtidos com $E_{1}$ e $B_{1}$. A interpretação possível para as mudanças observadas é que durante a competição na população das caixas, ocorreu uma seleção que igualou o tempo de desenvolvimento das larvas. Portanto, o efeito de idade diferente de uma larva sobre outra, de outro genótipo, desapareceu.

THE EFFECT OF THE MUTANT EBONY OF DROSOPHILA MELANOGASTER IN LARVAL VIABILITY

\section{SUMMARY}

Data of pre-adult viability of different genotypes for the locus ebony in samples of 100 larvae are presented for different compositions. Two different pairs of strains has been used, a pair of wild and ebony flies, $B_{1}$ and $E_{1}$ from the laboratory and another pair of wild and ebony, $\mathrm{B}_{2}$ and $\mathrm{E}_{2}$ extracted from a population cage after 20 generation of competition between both genotypes.

The results from the experiment with $\mathrm{B}_{2}$ and $\mathrm{E}_{2}$ flies are different from $B_{1}$ and $E_{1}$. The possible interpretation of the changes observed is that during the competition in the population cage selection for the same development time of larvae has occured. So, the effect of different ages of larvae from our genotype on the other desappears.

\section{INTRODUÇÃO}

O valor adaptativo de um genótipo é definido como sendo a capacidade, em relação a outros genótipos da mesma população, de deixar

Número especial em homenagem ao Prof. Dr. Paulo Sawaya, no ano jubilar de seu magistério. 
descendentes, ou seja, de contribuir para o conjunto gênico da próxima geração da população. Em Drosophila pode-se dizer que o valor adaptativo é a resultante da interação da fecundidade, fertilidade, viabilidade nas fases larval e adulta, tempo de desenvolvimento e seleção sexual. O comportamento seletivo em cada uma dessa etapas do ciclo reprodutivo determina, conforme suas características, consequências diferentes no destino do gene.

O presente trabalho visa obter algumas informações sobre o efeito do gene "ebony" na viabilidade larval. Vários trabalhos já tem analisado o mesmo problema sob diferentes aspectos. Moree, 1952, analisou o resultado do cruzamento entre heterozigotos para "ebony" em diferentes níveis de competição e mostrou que a viabilidade na fase larval do homozigoto "ebony" diminui à medida que a competição aumenta. Moree and King, 1961, observaram o mesmo efeito da competição, e mostraram que a viabilidade do heterozigoto é superior a ambos os homozigotos, mesmo quando a competição aumenta.

Dawood and Strickberger, 1964, mostraram que a viabilidade do "ebony" depende do grau de heterogozidade da cultura, confirmando assim os dados de Polivanov, 1964. Mostraram também que a vantagem do heterozigoto +/e está associada à taxa de desenvolvimento larval. Uma vez que a taxa de desenvolvimento das larvas de diferentes genótipos é diferente, é possivel que as larvas de uma idade exerçam influência sobre larvas de outras idades e que a interação entre as larvas se dê através de seus produtos do metabolismo que se difundem no meio da cultura. Essas duas hipóteses foram testadas por Dawood and Strickberger, 1969 a e b. Colocando em competição igual número de larvas + /e e e/e, com diferença de 24 horas de idade, observaram que os resultados são diferentes do controle, mas dependem da linhagem selvagem usada, podendo favorecer ou não o nascimento de "ebony" O mesmo resultado foi obtido quando analisaram a viabilidade larval em meio de culturas onde larvas, de genótipo igual ou diferente, já haviam sido mantidas, por dois dias. Existe influência, porém a intensidade e direção dependem do genótipo da larva précolocada no meio de cultura.

\section{MATERIAL E MÉTODO}

Este trabalho foi realizado com Drosophila melanogaster (Meigen, 1830). Foram usados dois estoques de moscas portadoras do 
mutante "ebony" (cr. III-70, 7) e dois estoques selvagens. Estes estoques diferem entre si pelas suas origens. Com dois estoques iniciais, Estoque Base-1 (B-1), selvagem, Estoque "ebony"-1 (E-1), os quais já foram descritos por Sene e Magalhães, 1971, foram iniciadas caixas de populações. Na 20. ${ }^{\text {a }}$ geração destas caixas foram reisoladas moscas selvagens e "ebony" e a partir delas foram obtidos os estoques Base-2 (B-2) e "ebony"-2 (E-2).

O estoque B-1 foi obtido em 1967, da mistura em partes iguais de moscas originárias de três conhecidas linhagens selvagens de $D$. melanogaster: Oregon-R, Canton-S e Samarkand, todos provenientes da Divisão de Biologia do Laboratório Nacional de Oak Ridge. Após a mistura, este estoque foi mantido em 140 vidros de $1 / 4$ de litro. A repicagem deste estoque foi sempre feita de modo a evitar um alto grau de endocruzamento, misturando-se os adultos de todos os vidros cada dois meses. O estoque E-1 foi obtido do cruzamento sucessivo de uma linhagem "ebony" com as linhagens Oregon-R, Canton-S e Samarkand para apresentar um "back-ground" genético semelhante ao do estoque B-1.

A manutenção de todos os estoques, foi feita em meio de cultura de fubá, cuja fórmula é a seguinte: fubá - 8,4\%; agar-agar - 1,7\%; mel - 8,4\%; fermento de padaria $-4,2 \%$; ácido propiônico - 1,0\%; água - 76,3\%. Os ovos foram analisados em meio de cultura com a seguinte composição: agar-agar — 1,5\%; açúcar — 2,5\%; água $96,0 \%$.

Os símbolos usados para indicação dos genótipos foram os seguintes: $+/+=$ genótipo selvagem; $+/ \mathrm{e}=$ genótipo heterozigoto filho de mãe selvagem; $\mathrm{e} /+=$ genótipo heterozigoto filho de mãe "ebony"; e/e = genótipo homozigoto "ebony" $\mathrm{Na}$ indicação dos cruzamentos, o primeiro indivíduo assinalado é sempre a fêmea. Assim, um cruzamento $+/+\mathrm{x}$ e/e significa fêmea homozigota selvagem cruzada com macho homozigoto "ebony".

A viabilidade absoluta de ovo a adulto foi estimada contando-se o número de moscas que atingiram o estágio adulto a partir de um número conhecido de ovos. Os ovos foram coletados após um período de duas horas de ovoposição e separados em lotes de 100; cada lote foi colocado em um vidro de excursão. Esta análise foi feita para caca genótipo; em algumas experiências colocaram-se 50 ovos de um genótipo em competição com 50 cvos de outro genótipo. 


\section{RESULTADO}

Foi estudada a viabilidade absoluta de ovo a adulto nas linhagens iniciais e nas linhagens extraídas das caixas de população depois de 20 gerações de competição.

A medida de viabilidade absoluta de ovo a adulto de cada classe genotípica foi obtida pela relação entre o número de ovos coletados e o número de adultos obtidos daqueles ovos. Os diferentes genótipos foram analisados isoladamente e em competição com o homozigoto e/e. A Tabela 1 apresenta a relação de experiências feitas com indicação dos genótipos dos pais usados para obtenção dos ovos e a composição da amostra de ovos analisados. Essas experiências são as mesmas, tanto para as linhagens iniciais como para as linhagens novas.

TABELA 1

Relação das experiências com as respectivas constituições genotípicas dos pais e dos ovos para os quais foram determinadas a viabilidade absoluta de ovo a adulto. De cada experiência foram realizadas 10 réplicas.

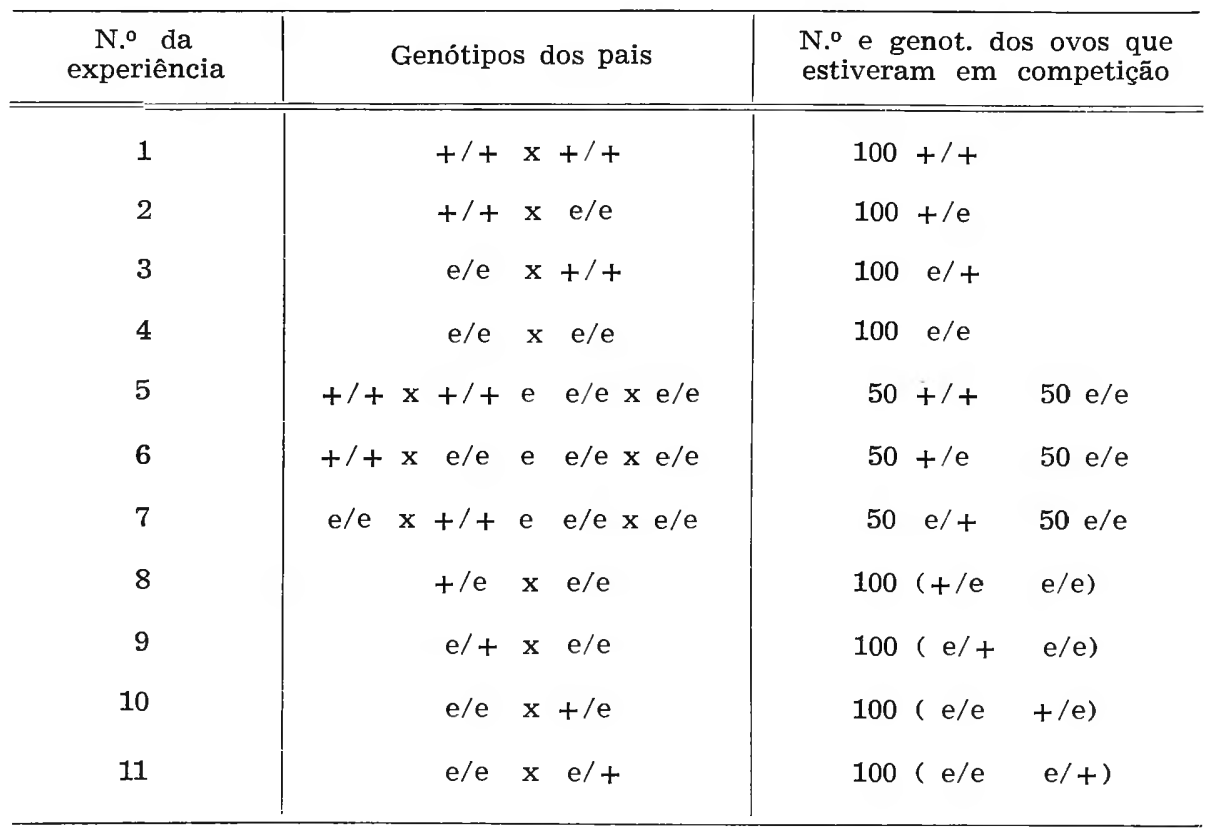


Resultados das Medidas nas Linhagens Iniciais

- Estoque $E-1$ e $B-1$

Os resultados das experiências em que só existe genótipo de um tipo em cada vidro (Exp. 1, 2, 3 e 4) encontram-se na Tabela 2.

\section{TABELA 2}

Número de adultos nascidos a partir de 100 ovos, nas 10 réplicas das experiências $1,2,3$ e 4 .

\begin{tabular}{|c|c|c|c|c|}
\hline N.o da réplica & $\begin{array}{c}\text { Exp. } 1 \\
+/+\end{array}$ & $\begin{array}{c}\text { Exp. } 2 \\
+/ \mathrm{e}\end{array}$ & $\underset{\mathrm{e} /+}{\text { Exp. }} 3$ & $\underset{\mathrm{e} / \mathrm{e}}{\operatorname{Exp}} 4$ \\
\hline 1 & 70 & 82 & 74 & 59 \\
\hline 2 & 85 & 97 & 73 & 72 \\
\hline 3 & 74 & 88 & 69 & 67 \\
\hline 4 & 73 & 64 & 78 & 80 \\
\hline 5 & 87 & 86 & 84 & 74 \\
\hline 6 & 55 & 88 & 75 & 73 \\
\hline 7 & 91 & 91 & 76 & 78 \\
\hline 8 & 70 & 82 & 81 & 64 \\
\hline 9 & 58 & 95 & 52 & 64 \\
\hline 10 & 78 & 89 & 80 & 59 \\
\hline Total & 741 & 862 & 742 & 690 \\
\hline
\end{tabular}


Os resultados das experiências nas quais competem 50 ovos de um tipo contra 50 ovos "ebony" (Exp. 5, 6, 7) encontram-se na Tabela 3 .

TABELA 3

Número de adultos nascidos de 50 ovos para cada genótipo, nas 10 réplicas das experiências 5,6 e 7 .

\begin{tabular}{|c|c|c|c|c|c|c|c|c|c|}
\hline \multirow{2}{*}{$\begin{array}{c}\text { N.o da } \\
\text { ré- } \\
\text { plica }\end{array}$} & \multicolumn{3}{|c|}{ Exp. 5} & \multicolumn{3}{|c|}{ Exp. 7} & \multicolumn{3}{|c|}{ Exp. 6} \\
\hline & $+/+$ & $e / e$ & Total & $+/ e$ & $e / e$ & Total & $e /+$ & e/e & Total \\
\hline 1 & 47 & 33 & 80 & 38 & 44 & 82 & 37 & 34 & 71 \\
\hline 2 & 32 & 26 & 58 & 45 & 35 & 80 & 24 & 12 & 36 \\
\hline 3 & 30 & 31 & 61 & 35 & 38 & 73 & 41 & 38 & 79 \\
\hline 4 & 44 & 30 & 74 & 44 & 35 & 79 & 38 & 31 & 69 \\
\hline 5 & 29 & 39 & 68 & 32 & 37 & 69 & 23 & 14 & 37 \\
\hline 6 & 39 & 34 & 73 & $3 \bar{i}$ & 40 & 77 & 40 & 31 & 71 \\
\hline 7 & 33 & 37 & 70 & 37 & 30 & 67 & 27 & 28 & 55 \\
\hline 8 & 40 & 27 & 67 & 42 & 38 & 80 & 19 & 21 & 40 \\
\hline 9 & 40 & 35 & 75 & 36 & 30 & 66 & 32 & 21 & 53 \\
\hline 10 & 33 & 13 & 46 & 41 & 40 & 81 & 25 & 17 & 42 \\
\hline Total & 367 & 305 & 672 & 387 & 367 & 754 & $3 乞 6$ & 247 & 553 \\
\hline
\end{tabular}

Os resultados das experiências nas quais competem larvas descendentes de ovos de diferentes genótipos (Exp. 8, 9, 10 e 11) encontramse na Tabela 4. 


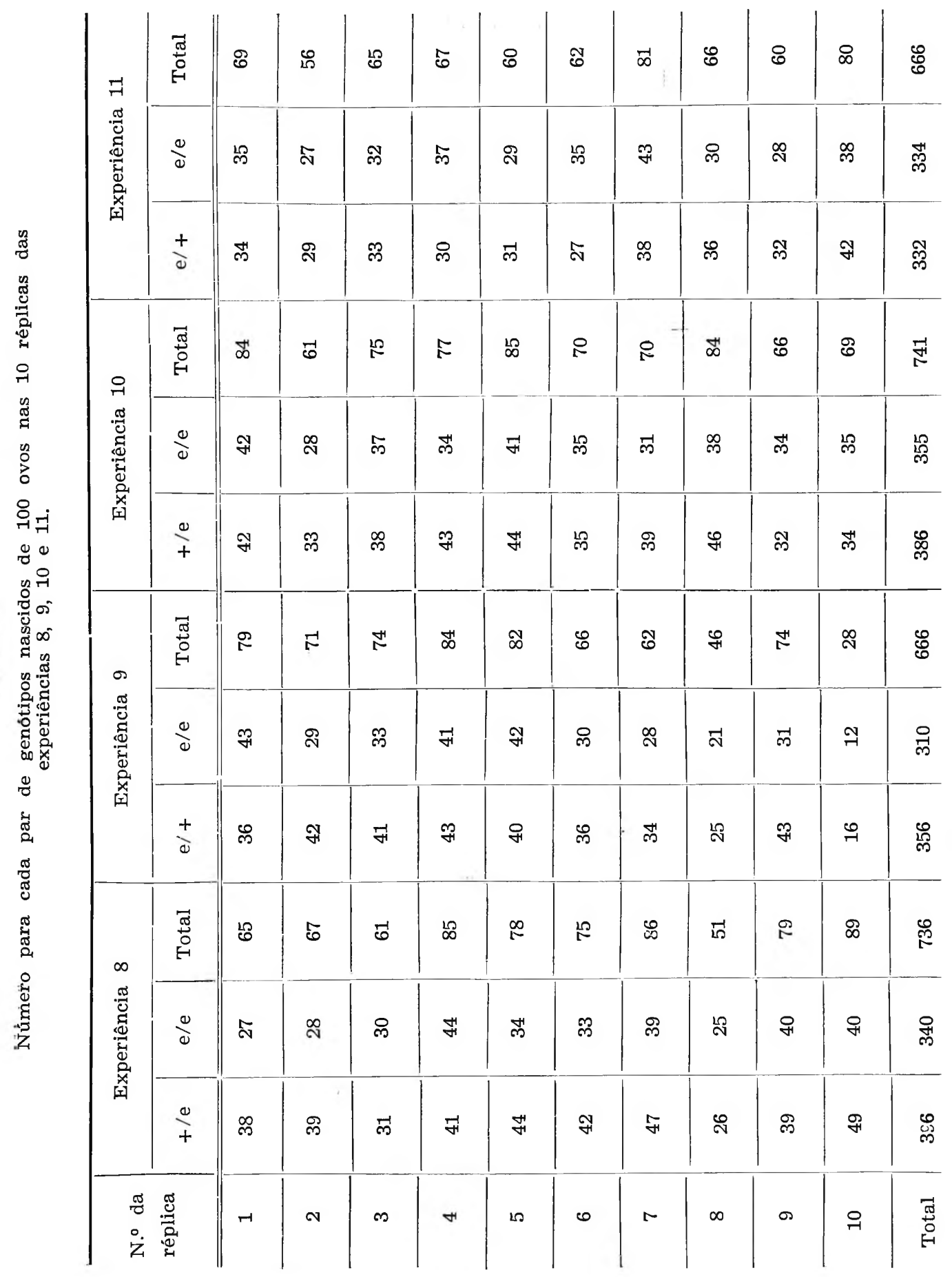


O resultado das experiências em que só existe genótipo de um tipo em cada vidro (Exp. 1, 2, 3, 4) encontram-se na Tabela 5.

\section{TABELA 5}

Número de adultos nascidos a partir de 100 ovos, nas 10 réplicas das experiências $1,2,3$ e 4 .

\begin{tabular}{c|c|c|c|c}
\hline N.o da réplica & $\begin{array}{c}\text { Exp. 1 } \\
+/+\end{array}$ & $\begin{array}{c}\text { Exp. 2 } \\
+/ \mathrm{e}\end{array}$ & $\begin{array}{c}\text { Exp. 3 } \\
\text { e/ }+\end{array}$ & $\begin{array}{c}\text { Exp. 4 } \\
\text { e/e }\end{array}$ \\
\hline 1 & 87 & 69 & 78 & 80 \\
2 & 89 & 78 & 73 & 75 \\
3 & 84 & 74 & 55 & 76 \\
4 & 69 & 91 & 75 & 82 \\
5 & 62 & 79 & 71 & 80 \\
6 & 73 & 74 & 75 & 63 \\
7 & 74 & 67 & 53 & 72 \\
8 & 91 & 62 & 57 & 71 \\
9 & 79 & 75 & 76 & 84 \\
\hline 10 & 83 & 71 & 79 & 747 \\
\hline
\end{tabular}

Os resultados das experiências nas quais competem 50 ovos de um tipo contra 50 ovos "ebony" (Exp. 5, 6, 7) encontram-se na Tabela 6 . 
TABELA 6

Número de adultos nascidos de 50 ovos para cada genótipo, nas 10 réplicas das experiências 5,6 e 7 .

\begin{tabular}{|c|c|c|c|c|c|c|c|c|c|}
\hline \multirow{2}{*}{$\begin{array}{l}\text { N. }{ }^{\circ} \text { da } \\
\text { ré- } \\
\text { plica }\end{array}$} & \multicolumn{3}{|c|}{ Exp. 5} & \multicolumn{3}{|c|}{ Exp. 6} & \multicolumn{3}{|c|}{ Exp. 7} \\
\hline & $+/+$ & e/e & Total & $+/ e$ & $e / e$ & Total & $e /+$ & $e / e$ & Total \\
\hline 1 & 21 & 16 & 37 & 30 & 26 & 56 & -19 & 27 & 36 \\
\hline 2 & 24 & 22 & 46 & 13 & 27 & 40 & 17 & 26 & 43 \\
\hline 3 & 25 & 36 & 61 & 34 & 25 & 59 & 24 & 29 & 53 \\
\hline 4 & 29 & 21 & 50 & 25 & 29 & 54 & 4 & 29 & 53 \\
\hline 5 & 25 & 33 & 58 & 19 & 32 & 51 & 20 & 37 & 57 \\
\hline 6 & 31 & 29 & 60 & 30 & 36 & 66 & 21 & 29 & 50 \\
\hline 7 & 17 & 26 & 43 & 20 & 22 & 42 & 12 & 37 & 49 \\
\hline 8 & 21 & 39 & 60 & 36 & 28 & 64 & 25 & 25 & 50 \\
\hline 9 & 22 & 29 & 51 & 17 & 19 & 36 & 24 & 23 & 47 \\
\hline 10 & - & - & - & 49 & 24 & 73 & 15 & 42 & 57 \\
\hline Total & 232 & 263 & 494 & 273 & 268 & 541 & 181 & 304 & 485 \\
\hline
\end{tabular}

O resultado das experiências nas quais competem larvas descendentes de ovos de diferentes genótipos (Exp. 8, 9, 10, 11) encontramse na Tabela 7 . 
F M. SENE e L. E. MAGALHAES

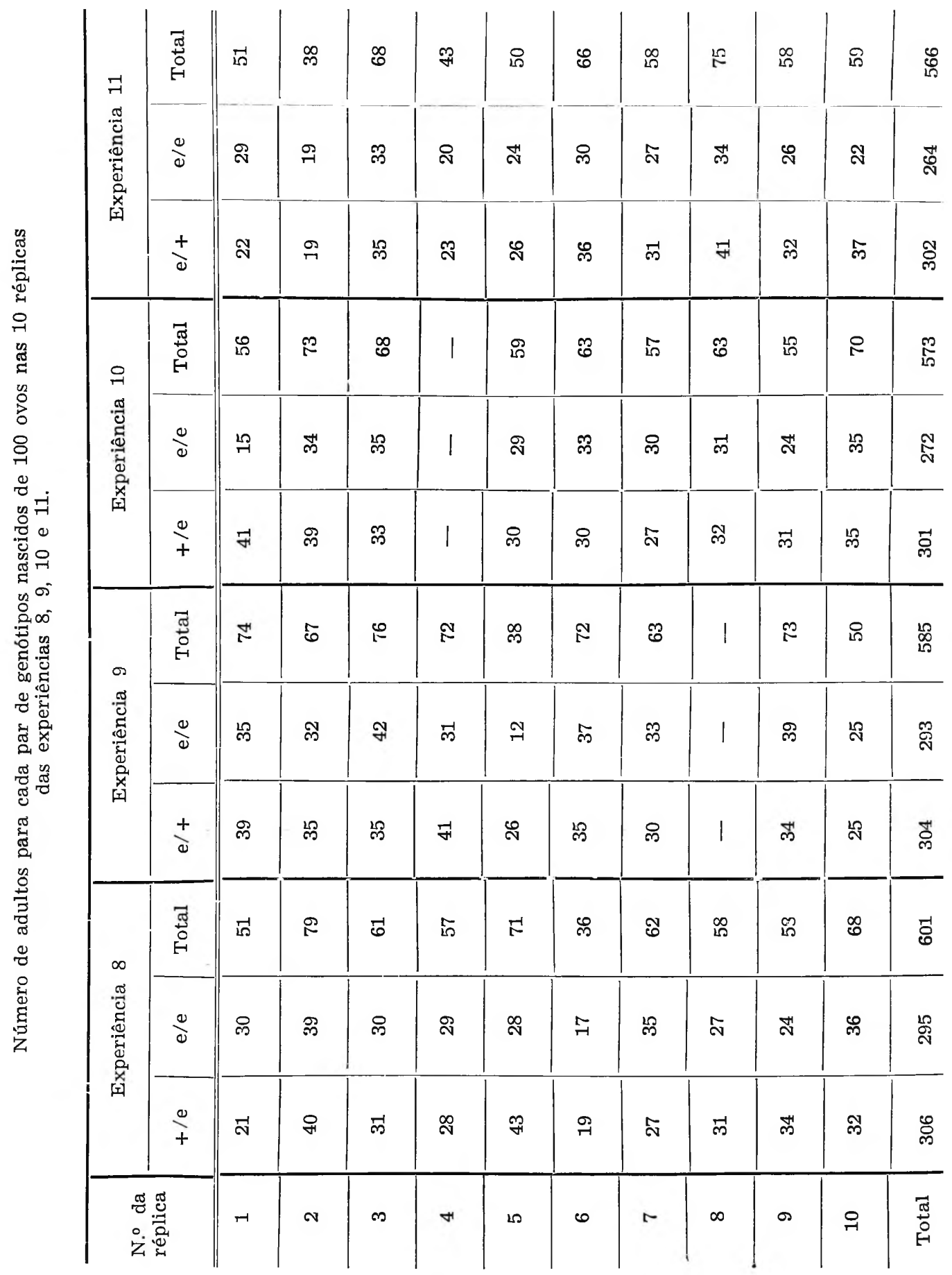


As análises de variância aplicadas aos dados da Tabela 2, mostram que a viabilidade de cada genótipo é diferente, apresentando a seguinte ordem $+/ \mathrm{e}>\mathrm{e} /+=+/+>\mathrm{e} / \mathrm{e}$.

A análise de variância aplicada aos dados da Tabela 3 mostra que a viabilidade do genótipo e/e varia significantemente de acordo com o genótipo com o qual ele esteja em competição. A sua viabilidade é maior quando compete com o genótipo $+/ \mathrm{e}$, menor com $+/+$ e menor ainda com $\mathrm{e} /+$.

$\hat{E}$ interessante constatar que alguns genótipos parecem favorecer a viabilidade do "ebony" Comparando-se as viabilidades do "ebony" numa cultura pura com sua viabilidade em competição, mas com a mesma densidade de população, isto é, 100 larvas por tubo, tem-se: "ebony" sozinho $=0,690$; "ebony" com selvagem $=0,610$; "ebony" com heterozigoto $+/ \mathrm{e}=0,734$ e "ebony" com heterozigoto $\mathrm{e} /+=$ 0,494. Verifica-se assim que o "ebony" junto com larvas +/e tem sua viabilidade aumentada, enquanto que "ebony" com heterozigoto $\mathrm{e} /+$ tem sua viabilidade bastante diminuida. O "ebony" pode também afetar a viabilidade da larva com a qual compete. Assim, por exemplo, a larva selvagem não é afetada, pois sozinha tem viabilidade de 0,740 e em competição, 0,734. Já a larva +/e passa, de viabilidade 0,860 para 0,770 e a larva e/+ passa, de 0,740 para 0,610 .

Essa é a pior combinação que existe, pois tanto a viabilidade do heterozigoto como a do "ebony" se reduz muito, assim é que para 1.000 ovos foram obtidos $742+/ \mathrm{e}, 690$ e/e e apenas 553 da mistura dos dois.

Na Tabela 4 apresentamos os dados de competição entre ovor heterozigotos e homozigotos para o gene "ebony" diferindo quanto ao genótipo dos pais; nas experiências 8 e 9 as mães são heterozigotas e nas experiências 10 e 11 os pais.

Como se pode ver pelos totais de cada experiência, quando a fêmea é heterozigota a diferença contra os indivíduos "ebony" é grande e quando os machos são heterozigotos, o número de "ebony" é maior ou igual ao de selvagens. É dificil concluir que haja seleção gamética, por que, como foi visto anteriormente, a viabilidade de larva depende do genótipo do competidor. Essa diferença deve ser bastante pronunciada, tendo em vista que os das experiências variam de modo que, quando entra no cruzamento macho ou fêmea de genótipo e/+, o número de descendentes é bem menor (666) do que no 
caso do genótipo envolvido ser o +/e. Essas diferenças são da mesma ordem de grandeza das que foram encontradas nas experiências 6 e 7 em que os totais foram 754 e 553.

Resultado das Medidas nas Linhagens Isoladas das Caixas - Estoque $E$-2 e $B$-2

Após 20 gerações em competição nas caixas, os estoques selvagens e "ebony" foram reisolados e repetiu-se os experimentos anteriores para se detectar possíveis mudanças no valor da viabilidade absoluta de ovo a adulto dos genótipos estudados.

Os cruzamentos das experiências realizadas com estes estoques são os mesmos que os da Tabela 1.

A análise de variância aplicada aos dados da Tabela 5, em que se mediu a viabilidade de cada genótipo isoladamente, mostra que não há diferença significante entre eles.

A análise de variância aplicada aos dados da Tabela 6 mostraram que a viabilidade do genótipo e/e quando em competição com os outros genótipos $+/+,+/ \mathrm{e}$ e $\mathrm{e} /+$, permanece constante. A viabilidade dos genótipos $+/+$, $+/$ e e e $/+$ também não diferem significantemente entre si, quando estes genótipos estão em competição com o genótipo e/e.

A viabilidade das larvas de cada genótipo é maior quando competem com larvas de genótipo igual ao seu (Exp. 1, 2, 3, 4) do que quando temos larvas de genótipos diferentes competindo em uma mesma cultura. Isto demonstra a existência de interferência de larvas de genótipos diferentes.

\section{DISCUSSÃO}

O fato do valor adaptativo de um gene ser o resultado da interação deste gene com o restante do patrimônio hereditário, e o fato deste patrimônio poder se alterar ao longo das gerações, faz com que o valor adaptativo dos alelos de um certo loco seja, em grande parte, dependente da arquitetura do patrimônio genético da população em que esses alelos se encontram. Vários trabalhos tem abordado este aspecto, dentre eles o de Strickberger, 1965, Jones e Barker, 1966, Ma- 
galhães, 1972 e Sene, 1972 (em experimentos com o próprio "ebony"), Franklin e Lewontin, 1970, e Shorrocks, 1970.

Dada a influência do patrimônio genético, e na impossibilidade de se obter linhagens selvagens e mutantes que difiram entre si apenas pelo loco mutante, tentou-se obter, para o presente trabalho, linhagens que apresentassem, pelo menos, a mesma variabilidade genética. Com esta intenção é que foram misturados os estoques CantonS, Oregon-R e o Samarkand. Esta mesma solução foi tentada por Grant e Mettler, 1969, que misturaram os estoques Canton-S, Oregon-R, Samarkand e o Swedish-B, obtendo uma linhagem que difere da usada no presente trabalho apenas por este último estoque.

Desta forma, este trabalho foi iniciado com as linhagens selvagem e mutante apresentando praticamente a mesma variabilidade genética (Estoque E-1 e B-1).

Quando colocadas em caixas de população a tendência dessas linhagens, se os cruzamentos forem ao acaso e as recombinações entrarem em equilíbrio, é de produzir uma população em que não existe mais diferenças quanto ao patrimônio genético entre as moscas "ebony" e selvagens.

A análise da viabilidade na fase de larva feita com os estoques E-2 e B-2 mostraram resultados bem distintos dos encontrados nas análises com os estoques iniciais, E-1 e B-1. Para os estoques E-1 e B-1, nas análises em que competiram larvas e/e com larvas $+/+$, $+/$ e e e/+, verificou-se que a viabilidade do genótipo e/e é sensivel a essa competição, havendo facilitação determinada pelo genótipo +/e e interferência determinada pelo genótipo $\mathrm{e} / \mathrm{t}$. Nesse particular é interessante observar a diferença de comportamento entre $+/ \mathrm{e}$ e e/ + , que é apenas citoplasmático. No caso das larvas e/+a interferência é recíproca e, em consequência, o número de nascimentos é bem menor do que o encontrado nas experiências em que compete larvas de um genótipo apenas. Foi mostrado também que essas variações da viabilidade são independentes do sexo.

Através das experiências para medir a viabilidade na fase larval, em que competem larvas de dois genótipos, comparando-se os resultados das experiências em que cada genótipo competitivo é proveniente de um cruzamento, com os resultados das experiências em que os dois genótipos competitivos são produzidos pelo mesmo cruzamento, foi possivel mostrar que não deve haver seleção gamética. $O$ 
mesmo Îenômeno já havia sido sugerido por Sene e Magalhães, 1971, sendo que mosiraram que havia um efeito do envelhecimento do espermatozčide portador do gene "ebony" sobre a viabilidade dos ovos de genótipo e/e.

Nas análises feitas com estoque E-2 e B-2 as medidas das viabilidades absolutas para os quatro genótipos considerados, na ausência de competição inter genotípica, deram diferenças estatisticamente não signiricantes. Nas experiências em que cada genótipo compete com o homozigoto e/e, verifica-se que não existe diferença entre eles quanto à viabilidade, porém todos os genótipos sofrem ưma redução em relação à viabilidade medida na ausência de competição. Portanto, a viabilidade do $\mathrm{e} / \mathrm{e}$ é igual às viabilidade dos genótipos $\mathrm{e} /+,+/ \mathrm{e} e$ $+/+$ quando compete com eles, exceto em uma das experiências na qual a viabilidade do e/e foi maior que a do $\mathrm{e} / \mathrm{t}$.

Os estoques E-2 e B-2 apresentam um comportamento diferente dcs estoques E-1 e B-1. Não se pode dizer que as diferenças entre os quatro genótipos se deva exclusivamente aos alelos do loco "ebony", tanto no caso de E-1 e B-1 como no caso de E-2 e B-2.

É provável que os estoques E-1 e B-1 diferissem entre si por maior número de genes que os estoques $\mathrm{E}_{\mathrm{A}}-2$ e B-2. Nas caixas, depois de 20 gerações os genes que afetavam a viabilidade larval foram sendo selecionadcs. Por outro lado pode-se pensar também que os efeitos manifestados nas análises com E-1 e B-1 não fossem independente do alelo "ebony", mas produto de interação desse alelo com outros genes do estoque. Convém salientar que tanto nas experiências com E-1 e B-1 como nas experiências de Moree e King, 1961 e de Dawood e Strickberger, 1964 o heterozigoto apresentava maior viabilidade, o que não ocorreu com os estoques E-2 e B-2. Segundo os dados de Dawood e Strickberger, 1969 a e b, o efeito competitivo entre larvas de diferentes genótipos se manifesta através de substâncias produzidas pəlas larvas mais velhas, que atuam sobre as mais novas. É possivel que os genes selecionados nos nossos experimentos foram os que determinam diferenças na taxa de desenvolvimento e que provocavam indiretamente diferença de viabilidade.

Desejamos expressar os nossos agradecimentos à FAPESP pelos auxílios concedidos ao nosso laboratório, que permitiram a execução dos trabalhos cujos 
resultados foram parcialmente apresentados. Somos gratos às Srtas. Vicentina Rodrigues Pereira e Rita de Cássia pela assistência técnica e a Sra. Reiko S. Rudzitis pela datilografia do original.

Ao Prof. Carlos Alberto Bragança Pereira pela assistência na parte estatística.

\section{B I B L I O G R A F I A}

DAWOOD, M. M. \& STRICKBERGER, M. W. (1964) - The effect of larval interaction on viability in $D$. melanogaster. I. Changes in heterozygosity. Genetics, 50:999-1007.

DAWOOD, M. M. \& STRICKBERGER, M. W. (1969 a) - The effect of larval interaction on viability in $D$. melanogaster. II. Changes in age structure. Genetics, $63: 201-11$.

DAWOOD, M. M. \& STRICKBERGER, M. W. (1969 b) - The effect of larval interaction on viability in Drosophila melagonaster. III. Effects of biotic residues. Genetics, 63:213-20.

FRANKLIN, I. \& LEWONTIN, R. C. (1970) - Is the gene the unit of seletion? Genetics, 65:707-34.

GRANT, B. \& METTLER, L. E. (1969) - Disruptive and stabilizing selection on the "Escape" behaviour of D. melanogaster. Genetics, 62:625-37.

JONES, L. P. \& BARKER, J. S. F. (1966) - Polymorphism at the ebony locus of Drosophila melanogaster and populations fitness. Genetics, 53:313-26.

MAGALHãES, L. E. (1972) - Estudo da seleção do mutante "ebony" $\in \mathrm{m}$ algumas fases do ciclo reprodutivo de $D$. melanogaster. Botucatu, 1972. [Tese - Livre Docência - Faculdade de Ciências Médicas e Biológicas de Botucatu].

MOREE, R. (1952) - Experimental measurement of the relative viability of the mutant ebony in D. melanogaster. Amer. nat., 86:45-48.

MOREE, R. \& KING, J. R. (1961) - Experimental studies on relative viability in D. melanogaster. Genetics, 46:1735-52.

POLIVANOV, S. (1964) - Selection in experimental populations of D. melanogaster with different genetic backgounds. Genetics, 50:81-100.

SENE, F. M. (1972) - Mudança do valor adaptativo do mutante "ebony" de D. melanogaster em caixas de população. São Paulo, 1972. [Tese Doutoramento - Dept. ${ }^{\circ}$ de Biologia do Instituto de Biociências da USP].

SENE, F. M. \& MAGALHÃES, L. E. (1971) - Valor adaptativo do mutante "ebony" de $D$. melanogaster em cruzamentos de laboratório: influência do genótipo e envelhecimento dos pais e do espermatozóide. Ciên. e Cult., 23: 8-20.

SHORROCKS, B. (1970) - The distribution of gene frequencies in polymorphic populations of $D$. melanogaster. Evolution, 24:660-9.

STRICKBERGER, M. W. (1965) - Comparative fitness of experimental populations of D. pseudoobscura. Heredity, 18:385-95. 
